\title{
Definitive Radiotherapy for Older Patients Aged $\geq 75$ Years With Localized Esophageal Cancer
}

\author{
GEN SUZUKI $^{1}$, HIDEYA YAMAZAKI $^{1}$, NORIHIRO AIBE $^{1}$, KOJI MASUI $^{1}$, TAKUYA KIMOTO $^{1}$, \\ DAISUKE SHIMIZU ${ }^{1}$, TAKESHI NISHIMURA ${ }^{1}$, AKIHIRO NAKASHIMA ${ }^{1}$, KAZUTAKA MACHIDA $^{1}$, \\ KANAKO KAWABATA ${ }^{1}$, YOSHIAKI OTA ${ }^{1}$, HITOSHI FUJIWARA ${ }^{2}$, TAKESHI ISHIKAWA ${ }^{3}$ and KEI YAMADA ${ }^{1}$ \\ ${ }^{1}$ Department of Radiology, Graduate School of Medical Science, \\ Kyoto Prefectural University of Medicine, Kyoto, Japan; \\ ${ }^{2}$ Department of Digestive Surgery, Graduate School of Medical Science, \\ Kyoto Prefectural University of Medicine, Kyoto, Japan; \\ ${ }^{3}$ Department of Gastroenterology and Hepatology, Graduate School of Medical Science, \\ Kyoto Prefectural University of Medicine, Kyoto, Japan
}

\begin{abstract}
Background/Aim: To evaluate the predictive factors in older patients with localized esophageal cancer treated with definitive radiotherapy. Patients and Methods: We retrospectively analyzed patients aged $\geq 75$ years who were treated with three-dimensional conformal radiotherapy between 2008 and 2017. The patients were classified into the oldest-old group ( $\geq 80$ years) and the old group (75-79 years). Results: Fifty patients were identified, 28 in the oldest-old group and 22 in the old group. Forty-six patients (92\%) completed the planned radiotherapy. The median follow-up time was 21 months. Two-year overall survival $(O S)$, disease-free survival, and locoregional control rates were $53 \%, 42 \%$, and $51 \%$, respectively. Univariate analyses for OS showed that neither the radiotherapy field nor total radiotherapy dose was a significant factor. Clinical $T$ stage, clinical $N$ stage, and age were independent predictors of $O S$. Conclusion: Age $\geq 80$ years is an independent prognostic factor for OS. Elective nodal irradiation and total radiotherapy dose above 50.4 Gy did not improve survival. Our findings may help in the treatment decisions for localized esophageal cancer in older patients.
\end{abstract}

This article is freely accessible online.

Correspondence to: Gen Suzuki, MD, Department of Radiology, Kyoto Prefectural University of Medicine, 465 Kajiicho Kawaramachi Hirokoji, Kamigyo-ku, Kyoto 602-8566, Japan. Tel: +81 752515618, Fax: +81 752515840, e-mail: gensuzu@koto.kpum.ac.jp

Key Words: Esophageal cancer, radiotherapy, chemoradiation, older patients, involved field radiation therapy, elective nodal irradiation.
The number of older individuals has rapidly increased in Japan. At present, people aged 65 years or older comprise $28.1 \%$ of the Japanese population, including $14.2 \%$ of the population in late-stage old age (aged 75 years or older) (1). Cancer is the leading cause of death in the older population. Aging in the Japanese population and increased life expectancy means that cancer in older adults is becoming an increasingly common social issue.

Esophageal cancer remains one of the most fatal cancers worldwide $(2,3)$. It occurs mainly in middle-aged and older people. In Japan, esophageal cancer was responsible for 11,483 deaths in 2016, accounting for $3.1 \%$ of all cancer deaths in the country. In 2013 , of the 22,812 patients with esophageal cancer in Japan, about half were older than 75 years (4). Although older patients with localized esophageal cancer are less subjected to aggressive treatment, any treatment, including palliative care, may be associated with an improved survival rate (5). Despite progress in surgical techniques, esophagectomy is associated with significant morbidity and mortality, and 75 years is often considered the age limit for this type of surgery (6). For patients who are either deemed medically inoperable or have tumors that are unresectable, the efficacy of definitive chemoradiation (CRT) has been established in numerous randomized, controlled trials (7, 8). The 2018 National Comprehensive Cancer Network guidelines recommend definitive CRT with fluorouracil and cisplatin, using a radiotherapy (RT) dose of $50.4 \mathrm{~Gy}$ as the standard care for patients with esophageal cancer who are not suitable for surgery (9). However, older patients are under-represented in these trials $(7,8)$, and little is known about data on the efficacy and safety of definitive RT for patients older than 75 years with localized esophageal cancer. RT is a less invasive treatment for localized esophageal cancer than surgery. Nevertheless, in reality, 
many physicians are hesitant to deliver curative RT to older patients because of its severe toxicity.

The aim of the present study was to retrospectively assess the feasibility, toxicities, and treatment outcomes of definitive RT for patients aged 75 years and older with localized esophageal cancer.

\section{Patients and Methods}

Study design and population. The study included patients aged 75 or older with localized esophageal cancer who received RT with or without concomitant chemotherapy at our institution between June 2008 and December 2017. The patients were classified into two groups: the oldest-old group, which included patients who were 80 years of age or older, and the old group, which included patients who were 75 to 79 years of age. The inclusion criteria were age 75 years or older, histologically proven squamous cell carcinoma of the esophagus, Eastern Cooperative Oncology Group performance status (PS) $\leq 2$, and no previous surgical resection. Patients were excluded if they had distant metastases other than metastases to the celiac or supraclavicular lymph nodes. At our hospital, almost all patients with clinical stage I esophageal cancer are advised to undergo endoscopic submucosal dissection (ESD) because of the favorable local control rate and good safety of this approach (10, 11). All patients with stage I esophageal cancer, except those with a pT1a tumor with a negative resection margin and no lymphovascular invasion, received additional RT after ESD. Six patients who underwent ESD before RT/CRT were included in this study. Lymph node or distant metastases were ruled out with contrast-enhanced computed tomography (CT) from the neck to the abdomen, and positron emission tomography/CT of the whole body. Disease stage was based on the 7th edition of the TNM classification (International Union against Cancer TNM classification; UICC 2009) (12). The study was approved by the institutional review board of the Kyoto Prefectural University of Medicine (approval number ERB-C-1334). Written informed consent was obtained from each patient prior to the treatment for the publication of this article and any accompanying images.

Treatment. CT-based radiation planning and three-dimensional conformal RT (3DCRT) were used for the patients. All patients were treated by conventional fractionation (1.8-2 Gy per fraction; one fraction per day, and five fractions per week). The bilateral supraclavicular, periesophageal, mediastinal, and perigastric lymph node areas were considered regional lymph node areas. Prophylactic RT involving these lymph node areas was considered for elective nodal irradiation (ENI). The gross tumor volume (GTV) was expanded to the clinical tumor volume (CTV) by extending the margin 2 to $3 \mathrm{~cm}$ superiorly and inferiorly, and $0.5 \mathrm{~cm}$ laterally. The CTV included the prophylactic regional lymph nodes along with the primary tumor in patients receiving ENI, and the GTV with an optional part of the regional lymph nodes in patients receiving involved-field RT (IFRT). The planning target volume was defined as the CTV plus a $1-\mathrm{cm}$ margin in all directions in the initial and boost plans. In patients receiving IFRT, a dose of 39.6 to $40 \mathrm{~Gy}$ in 20 to 22 fractions was delivered to the anterior/posterior opposed portals or four anterior/posterior and oblique portals. After the initial plan was completed, a boost of 10-20 Gy was delivered to the primary tumor and the metastatic lymph nodes. In patients with negative resection margins who underwent ESD, the boost plans were omitted. The treatment fields were adjusted using a multileaf collimator in order to reduce the maximal dose delivered to the spinal cord to $<40 \mathrm{~Gy}$. The use of chemotherapy and the regimen were determined by the physicians according to each patient's general condition, clinical course, and function of organs, such as the kidneys, liver, heart, and bone marrow.

Follow-up and evaluation. All patients were followed up to detect local recurrence or distant metastases every 3 to 4 months during the first 2 years, and every 6 months thereafter. Follow-up involved blood tests, upper gastrointestinal endoscopy, and CT of the neck, chest, and abdomen. Follow-up data were obtained from electronic medical records.

Statistical analysis. The baseline characteristics of patients in the two age groups were compared using the Mann-Whitney $U$-test for continuous variables and the $\chi^{2}$ test or Fisher's exact test for categorical variables. Overall survival (OS) was measured from the date of treatment initiation to the date of the last follow-up or death from any cause. Disease-free survival (DFS) was measured from the date of treatment initiation to the date of the first observation of any recurrence. Locoregional control (LRC) was measured from the date of treatment initiation to the date of local or regional lymph node recurrence. OS, DFS, and LRC were calculated by the KaplanMeier method, starting from the day when the initial treatment began. In univariate analyses, differences between the groups were estimated by the log-rank test. Cox regression was used to perform multivariate analyses. Toxicities were scored according to the National Cancer Institute Common Terminology Criteria for Adverse Events, version 4.0. All statistical analyses were performed with EZR (Saitama Medical Center, Jichi Medical University, Saitama, Japan), a graphical user interface for R (The R Foundation for Statistical Computing, Vienna, Austria, version 2.13.0). More precisely, it is a modified version of $\mathrm{R}$ commander (version 1.6-3) that was designed to add statistical functions frequently used in biostatistics (13). In all analyses, $p<0.05$ was considered to indicate a statistically significant difference.

\section{Results}

Characteristics of patients and tumors. A total of 50 patients were enrolled in the study, 28 patients (56\%) in the oldestold group and 22 patients (44\%) in the old group. The backgrounds and treatments of patients in the two groups are summarized in Table I. The median age of patients in the oldest-old group and the old group was 82 years (range $=80$ 88 years) and 77 years (range $=75-79$ years), respectively. The use of concurrent chemotherapy in the oldest-old group was significantly lower than that in the old group $(p=0.006)$. No significant between-group differences were observed in the sex ratio, PS, tumor location, TNM stage, RT field, or total RT dose. With regard to the regimen of concurrent chemotherapy, 17 patients (six in the oldest-old group and eleven in the old group) received two cycles of 5-fluorouracil and cisplatin, eleven patients (five in the oldest-old group and sic in the old group) received one cycle of 5-fluorouracil and cisplatin, 4 patients ( 2 in the oldest-old group and 2 in 
Table I. Characteristics of patients and tumors.

\begin{tabular}{|c|c|c|c|}
\hline Characteristic & $\begin{array}{l}\text { Old } \\
\text { group } \\
(\mathrm{n}=22)\end{array}$ & $\begin{array}{l}\text { Oldest-old } \\
\text { group } \\
(\mathrm{n}=28)\end{array}$ & $p$-Value \\
\hline \multicolumn{4}{|l|}{ Age (yr) } \\
\hline Median (range) & $77(75-79)$ & $82(80-88)$ & \\
\hline \multicolumn{4}{|l|}{ Gender, $\mathrm{n}$} \\
\hline Male & 16 & 25 & 0.16 \\
\hline Female & 6 & 3 & \\
\hline \multicolumn{4}{|l|}{ Performance status, $\mathrm{n}$} \\
\hline 0 & 13 & 13 & 0.55 \\
\hline 1 & 3 & 7 & \\
\hline 2 & 6 & 8 & \\
\hline \multicolumn{4}{|l|}{ Main tumor location, $\mathrm{n}$} \\
\hline Upper thorax & 6 & 10 & 0.19 \\
\hline Middle thorax & 10 & 6 & \\
\hline Lower thorax & 6 & 12 & \\
\hline \multicolumn{4}{|l|}{ T stage, $\mathrm{n}$} \\
\hline $\mathrm{T} 1-2$ & 12 & 16 & $>0.99$ \\
\hline T3-4 & 10 & 12 & \\
\hline \multicolumn{4}{|l|}{$\mathrm{N}$ stage, $\mathrm{n}$} \\
\hline No & 10 & 18 & 0.25 \\
\hline $\mathrm{N} 1-3$ & 12 & 10 & \\
\hline \multicolumn{4}{|l|}{ M stage, $n$} \\
\hline M0 & 22 & 24 & 0.12 \\
\hline $\begin{array}{l}\text { M1 (supraclavicular/ } \\
\text { abdominal lymph nodes) }\end{array}$ & 0 & 4 & \\
\hline \multicolumn{4}{|l|}{ Concurrent chemotherapy, $\mathrm{n}$} \\
\hline Yes & 21 & 17 & 0.006 \\
\hline No & 1 & 11 & \\
\hline \multicolumn{4}{|l|}{ Radiation field, $\mathrm{n}$} \\
\hline ENI & 6 & 7 & $>0.99$ \\
\hline IFRT & 16 & 21 & \\
\hline \multicolumn{4}{|l|}{ Total radiation dose, $\mathrm{n}$} \\
\hline$\leq 50.4 \mathrm{~Gy}$ & 7 & 12 & 0.56 \\
\hline$>50.4 \mathrm{~Gy}$ & 15 & 16 & \\
\hline
\end{tabular}

ENI: Elective nodal irradiation; IFRT: involved-field radiotherapy.

the old group) received two cycles of 5-fluorouracil and nedaplatin, 1 patient in the oldest-old group received cisplatin, 1 patient in the oldest-old group received $S-1$, and 1 patient in the old group received docetaxel.

Compliance with treatment. Forty-six patients (92\%) completed the planned RT. The median total RT dose was 60 Gy (range=8-60 Gy). Four patients (two each in the oldest-old group and the old group) did not complete RT for the following reasons. Two oldest-old patients who received ENI discontinued treatment at 18 and 44 Gy because of pneumonia. In the other two patients (both in the old group), CRT was discontinued at 38 and 8 Gy because of severe nausea and arrhythmia, respectively.

Treatment outcomes. The median observation period was 21 months (range=3-112 months). Among the 50 patients, 22

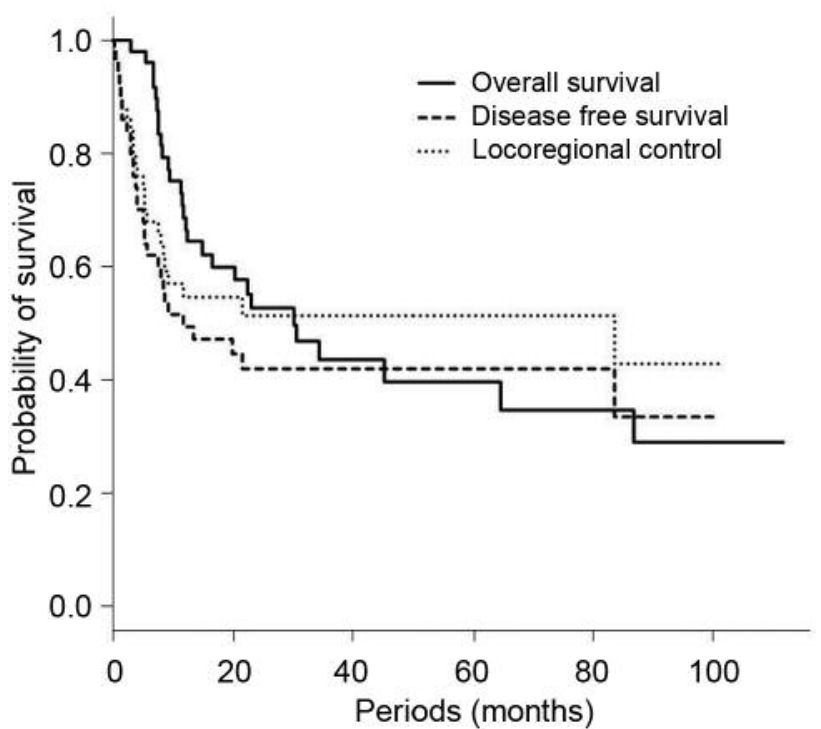

Figure 1. Overall survival, disease-free survival, and locoregional control rate for older patients with localized esophageal cancer treated with radiotherapy.

(44\%) died of esophageal cancer and six (12\%) died of other causes during the study period. Recurrence was observed in 29 patients (58\%): local recurrence in $13(26 \%)$, regional lymph node metastases in $5(10 \%)$, distant metastases in 5 $(10 \%)$, and both local and lymph node recurrence in six $(12 \%)$. Lymph node metastasis as the first recurrence site in the IFRT group was observed in 4 patients. Among them, nodal relapse outside the IFRT volume occurred in 3 patients. In the ENI group, one patient experienced in-field nodal relapse as the first recurrence site. The 2-year rates of OS, DFS, and LRC were 53\%, 42\%, and 51\%, respectively (Figure 1). As shown in Figure 2A, there was tendency toward better OS in the old group $(61 \%)$ compared to the oldest-old group (44\%) after 2 years $(p=0.07)$. Two-year DFS in the oldest-old group and the old group was $41 \%$ and $49 \%$, respectively; the difference between the two groups was not statistically significant $(p=0.45)$ (Figure 2B).

Prognostic analysis. Univariate analysis of OS rate was performed according to the patient's age, sex, PS, tumor location, $\mathrm{T}$ stage, $\mathrm{N}$ stage, concurrent chemotherapy, RT field, and total RT dose. Among these factors, the correlations between OS and PS, T stage, N stage, and concurrent chemotherapy were statistically significant. The 2-year OS rates were $66 \%$ versus $38 \%$ for PS0 versus PS1$2(p=0.047), 79 \%$ versus $19 \%$ for T1-2 versus T3-4 $(p<0.001), 73 \%$ versus $27 \%$ for N0 versus N1-3 $(p=0.002)$, and $25 \%$ versus $62 \%$ for RT alone versus concurrent chemoradiation (CCRT) $(p=0.002)$. There were no significant differences in the RT field or total RT dose. We 

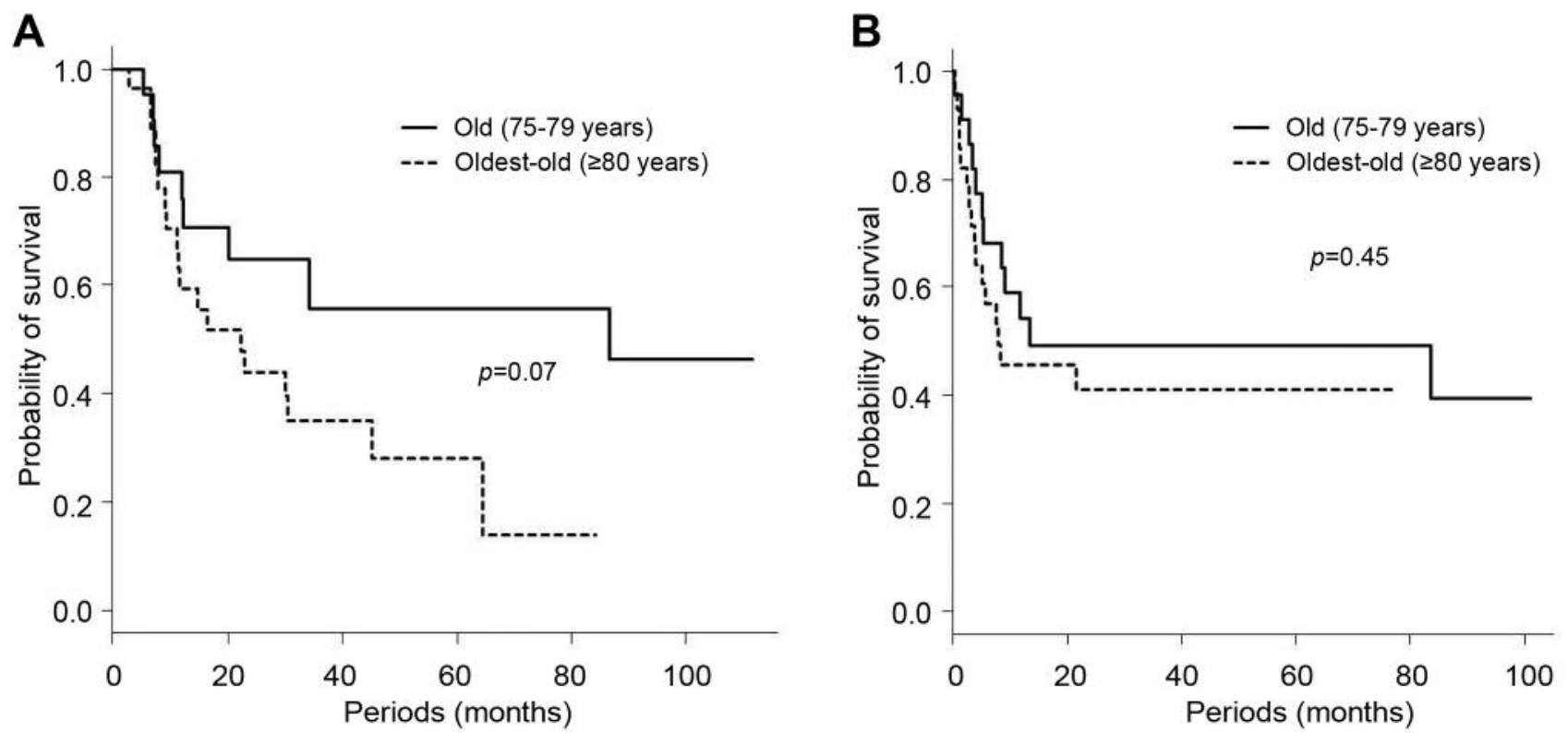

Figure 2. Overall survival rate and disease-free survival rate by age group. A. Overall survival rate. The oldest-old group had $44 \%$ overall survival at 2 years, whereas that in the older group was $61 \%(p=0.07)$. B. Disease-free survival rate. The oldest-old group had $41 \%$ disease-free survival at 2 years, whereas that in the older group was $49 \%(p=0.45)$.

performed further multivariate analysis for OS according to the patient's age, PS, T stage, $\mathrm{N}$ stage, and concurrent chemotherapy. The analysis showed that age (75-79 years, $p=0.03, \mathrm{HR}=0.34,95 \% \mathrm{CI}=0.12-0.91), \mathrm{T}$ stage $(\mathrm{T} 1-2$, $p<0.005, \mathrm{HR}=0.18,95 \% \mathrm{CI}=0.07-0.42)$, and $\mathrm{N}$ stage $(\mathrm{N} 0$, $p=0.02, \mathrm{HR}=0.36,95 \% \mathrm{CI}=0.15-0.87)$ were independent prognostic factors of OS (Table II).

Toxicity. A grade $\geq 3$ acute adverse event (AE) was observed in 25 patients $(50 \%)$. The most commonly observed AE was leukocytopenia, which was observed in 13 patients (26\%), mainly in the old group (Table III). Acute grade 3 anorexia was observed in four patients (8\%), and grade 3 esophagitis in two patients (4\%). Two patients in the oldest-old group suffered from acute grade 3 or 4 pneumonitis. Nine patients (18\%) were observed to have a late grade $\geq 3 \mathrm{AE}$ during the follow-up. The most common late $\mathrm{AE}$ was pneumonia, which was observed in three patients. Two patients (4\%) had a late grade $5 \mathrm{AE}$ (pericardial tamponade and pneumonitis). The results for patients who had a late grade $\geq 3 \mathrm{AE}$ are summarized in Table IV.

\section{Discussion}

Life expectancy in Japan is the highest in the world, and it keeps on increasing (1). Because of the high proportion of older patients, it seemed reasonable to elevate the cut-off point for defining older patients to 75 years in this study. In general, the response to cancer treatment is different in older and younger patients. It is hoped that future studies will further develop RT for localized esophageal cancer, including for older patients. Most of what we know about RT for older patients with esophageal cancer has been learned from studies on patients over the age of 70 (14-18), and data on the efficacy and safety for patients over the age of 75 are limited $(19,20)$. Many studies included patients with all clinical stages of esophageal cancer, including M1 (distant organ metastases), and little is known about definitive RT in older patients with localized esophageal cancer.

Our results showed that RT in older patients resulted in good OS, with 2-year estimated OS, DFS, and LRC of 53\%, $42 \%$, and $51 \%$, respectively, and a median OS time of 30 months (Figure 1). Interestingly, our results were comparable to or slightly better than those of previous studies on patients younger than those in our study $(14,18,21-23)$ (Table V). In addition, only $10 \%$ of patients failed at distant sites, which is relatively low compared to the literature in which about 13$37 \%$ is expected $(7,8,14,18,23)$. One reason for these may be that our study included a relatively large number of patients with early-stage cancers. Age is an independent prognostic factor of OS in our study, which is different from the results of other studies $(14,18,23)$. Huang et al. suggested EC patients aged $\geq 80$ benefit from RT only if the cancer is in localized/regional stage (24). Functional and cognitive impairment, depression and social isolation are prevalent in older patients with esophageal cancer, and associate with adverse health outcomes (25). Thus, basically, advanced age itself is not enough reason to be excluded for RT. 
Table II. Predictive factors of overall survival in univariate and multivariate analysis.

\begin{tabular}{|c|c|c|c|c|c|c|}
\hline \multirow[b]{2}{*}{ Variable } & & \multicolumn{2}{|c|}{ Univariate analysis } & \multicolumn{3}{|c|}{ Multivariate analysis } \\
\hline & & 2-year OS (\%) & $p$-Value & HR & $95 \% \mathrm{CI}$ & $p$-Value \\
\hline \multicolumn{7}{|l|}{ Age $(y r), n$} \\
\hline $75-79$ & 22 & 61 & 0.07 & 0.34 & $0.12-0.91$ & 0.03 \\
\hline$\geq 80$ & 28 & 44 & & 1.00 & & \\
\hline \multicolumn{7}{|l|}{ Gender, $\mathrm{n}$} \\
\hline Male & 41 & 50 & 0.21 & & & \\
\hline Female & 9 & 62 & & & & \\
\hline \multicolumn{7}{|l|}{ Performance status, $\mathrm{n}$} \\
\hline 0 & 26 & 66 & 0.047 & 0.96 & $0.37-2.46$ & 0.93 \\
\hline $1-2$ & 24 & 38 & & 1.00 & & \\
\hline \multicolumn{7}{|l|}{ Main tumor location, $\mathrm{n}$} \\
\hline Upper thorax & 16 & 43 & 0.29 & & & \\
\hline Middle/lower thorax & 34 & 58 & & & & \\
\hline \multicolumn{7}{|l|}{ T stage, $n$} \\
\hline $\mathrm{T} 1-2$ & 28 & 79 & $<0.001$ & 0.18 & $0.07-0.42$ & $<0.005$ \\
\hline T3-4 & 22 & 19 & & 1.00 & & \\
\hline \multicolumn{7}{|l|}{$\mathrm{N}$ stage, $\mathrm{n}$} \\
\hline No & 28 & 73 & 0.002 & 0.36 & $0.15-0.87$ & 0.02 \\
\hline N1-3 & 22 & 27 & & 1.00 & & \\
\hline \multicolumn{7}{|c|}{ Concurrent chemotherapy, $\mathrm{n}$} \\
\hline No & 12 & 25 & 0.002 & 0.55 & $0.18-1.66$ & 0.22 \\
\hline Yes & 38 & 62 & & 1.00 & & \\
\hline \multicolumn{7}{|l|}{ Radiation field, $\mathrm{n}$} \\
\hline ENI & 13 & 48 & 0.69 & & & \\
\hline IFRT & 37 & 54 & & & & \\
\hline \multicolumn{7}{|l|}{ Total radiation dose, $\mathrm{n}$} \\
\hline$\leq 50.4 \mathrm{~Gy}$ & 19 & 67 & 0.18 & & & \\
\hline$>50.4 \mathrm{~Gy}$ & 31 & 46 & & & & \\
\hline
\end{tabular}

OS: Overall survival; ENI: elective nodal irradiation; IFRT: involved-field radiotherapy; HR: hazard ratio; 95\%CI: 95\% confidence interval.

In general, older patients have decreased tolerance to chemotherapy. Some previous studies suggested that CCRT even in older patients had survival benefits compared with RT alone $(14,15,17,26)$. However, most of these studies targeted patients over 70 years of age and not patients over 75 years of age. In the study by Zhang et al., multivariate analysis revealed that survival was significantly better in the CCRT group than in the RT alone group for patients 72 years of age or less (26). Zhao et al., retrospectively analyzed 149 patients over 75 years of age with esophageal cancer and reported that there was no statistically significant survival benefit from CCRT compared with RT alone (19). Some studies have reported that most patients aged 80 years or more are unlikely to tolerate chemotherapy $(27,28)$. The results of our study do not contradict these reports. In our study, four patients did not complete the planned RT because of severe acute toxicities, and two of them received CCRT. Incomplete or interrupted courses of RT can compromise the efficacy of treatment as well as the ability to deliver higher doses of RT in the future. Therefore, CRT should be used with caution for patients aged 75 or older; omission or modification of the dose of chemotherapy may be necessary to reduce toxic side effects.
Table III. Acute grade $\geq 3$ adverse events.

\begin{tabular}{lcc}
\hline Adverse event & $\begin{array}{c}\text { Old group } \\
(\mathrm{n}=22)\end{array}$ & $\begin{array}{c}\text { Oldest-old group } \\
(\mathrm{n}=28)\end{array}$ \\
\hline Hematological & 1 & 1 \\
$\quad$ Anemia & 8 & 5 \\
Leukocytopenia & 0 & 0 \\
$\quad$ Thrombopenia & 2 & 2 \\
Nonhematological & 1 & 1 \\
Anorexia & 0 & 2 \\
Esophagitis & 1 & 1 \\
Pneumonitis & 1 & 0 \\
Renal dysfunction & 1 & 0 \\
Pulmonary emboli & & \\
Arrhythmia & 13 & 11 \\
Any grade 3 adverse event & 0 & 1 \\
Any grade 4 adverse event & & \\
\hline
\end{tabular}

ENI did not improve the clinical outcomes in our study. IFRT has been widely used for patients with esophageal cancer in clinics, but the RT fields are still controversial 
Table IV. Late grade $\geq 3$ adverse events.

\begin{tabular}{|c|c|c|c|c|c|c|c|}
\hline Age (yr) & Gender & PS & Adverse event & Grade & RT field & CCRT & Total RT dose (Gy) \\
\hline 80 & M & 0 & Pleural effusion & 3 & IFRT & + & 40 \\
\hline 82 & M & 2 & Abdominal abscess & 3 & IFRT & - & 40 \\
\hline 84 & M & 0 & Pericardial tamponade & 5 & IFRT & + & 60 \\
\hline 84 & M & 0 & Pneumonitis & 3 & ENI & + & 60 \\
\hline 81 & M & 0 & Anorexia & 3 & ENI & + & 60 \\
\hline 82 & M & 1 & Esophageal strictures & 3 & IFRT & + & 60 \\
\hline 78 & $\mathrm{~F}$ & 2 & Anorexia & 3 & IFRT & + & 60 \\
\hline 79 & M & 2 & Pneumonitis & 5 & IFRT & + & 60 \\
\hline 78 & $\mathrm{~F}$ & 0 & Pneumonitis & 3 & IFRT & + & 60 \\
\hline
\end{tabular}

PS: Performance status; ENI: elective nodal irradiation; IFRT: involved-field radiotherapy; CCRT: concurrent chemoradiation; RT: radiotherapy.

Table V. Published studies including the age and outcome of radiotherapy for older patients with localized esophageal cancer.

\begin{tabular}{lcccccccc}
\hline Authors (reference) & Year & Country & $\mathrm{n}$ & Age (yr) & Median age (yr) & Treatment & Median OS (mo) & 2-year OS (\%) \\
\hline Anderson et al. (21) & 2007 & USA & 23 & $\geq 66$ & 77 & CCRT & 35 & 64 \\
Tougeron et al. $(18)$ & 2008 & France & 109 & $\geq 70$ & 74.4 & CCRT & 15.2 & 35.5 \\
Go et al. (22) & 2012 & Korea & 57 & $\geq 65$ & 69 & CCRT & 11.2 & NR \\
Song et al. $(23)$ & 2015 & China & 82 & $\geq 70$ & 76.4 & CCRT & 26.9 & NR \\
Zhao et al. (14) & 2017 & China & 183 & $\geq 70$ & 76 & CCRT & 18.6 & 43.5 \\
Current study & & Japan & 50 & $\geq 75$ & 80 & CCRT/RT & 30 & 53 \\
\hline
\end{tabular}

OS: Overall survival; CCRT: concurrent chemoradiation; RT: radiotherapy; NR: not reported.

between ENI and IFRT. A recent meta-analysis revealed that OS and LRC for IFRT were not inferior to those for ENI, even for tumors located in the cervical and upper thoracic esophagus (29). IFRT also decreased the incidence of lung and esophageal toxicities with less RT volume compared with ENI (30). In our study, the pattern of recurrence revealed the dominance of the intra-RT field over distant areas, and in fact, most of the recurrences included the primary site. This finding suggests that IFRT might also be favorable for older patients.

In our study, fewer patients received CCRT in the oldestold group (more than 80 years) compared to the old group (7579 years old), so the therapeutic intensity of the oldest-old group is likely to be lower than that of the old group. Nevertheless, the rate of late grade $\geq 3$ AEs was $21 \%(6 / 28)$ in the oldest-old group and $14 \%(3 / 22)$ in the old group. Although this study did not provide clear answers on the relationship between age and the risk of severe complications, age seems to be associated with that risk. A total RT dose above 50.4 Gy did not improve OS and also seemed to be associated with severe late AE. Radiation oncologists, like all clinicians caring for older patients with cancer, must be careful about potentially overtreating older adults, with substantial competing risks of non-cancer deaths. Modern RT techniques typified by IMRT facilitate maximizing the delivery of RT to the planned treatment volume, while limiting the risk of radiation-induced damage to normal surrounding tissues and organs. On the basis of IMRT, a definitive RT dose of $\geq 60 \mathrm{~Gy}$ has yielded more favorable survival outcomes than a standard dose of 50.4 Gy in some recent studies $(31,32)$, and a similar effect could be found in the older population without increasing treatment-related toxicities (17). Modern RT techniques may be a promising therapeutic tool for older patients in the future.

Our study had several limitations, including its retrospective design, small sample size, and short follow-up period, which may have limited its statistical power. A larger study with standardized, uniform procedures should be performed to validate our results. In conclusion, age $\geq 80$ years is an independent prognostic factor for OS. Elective nodal irradiation and total radiotherapy dose above $50.4 \mathrm{~Gy}$ did not improve survival. Our findings may help in the treatment decisions for localized esophageal cancer in older patients aged $\geq 75$ years.

\section{Conflicts of Interest}

None of the Authors have any conflict of interest to disclose regarding this study. 


\section{Authors' Contributions}

Study concept: G. Suzuki; Study design: G. Suzuki, H. Fujiwara, T. Ishikawa; Data collection: G. Suzuki, N. Aibe, K. Masui, T. Kimoto, D. Shimizu, T. Nishimura, A. Nakashima, K. Machida, K. Kawabata, Y. Ota. Quality control of data and algorithm: G. Suzuki, H. Yamazaki; Analysis and interpretation of data: G. Suzuki, H. Yamazaki; Statistical analysis: G. Suzuki, H. Yamazaki; Manuscript preparation: G. Suzuki. Manuscript editing: G. Suzuki, H. Yamazaki, K. Yamada; Manuscript review: G. Suzuki, H. Fujiwara, T. Ishikawa; All authors approved the final version of the manuscript.

\section{References}

1 Barron JP: Statics Bureau, Ministry of Internal Affairs and Communications. Population estimates by age (5-year age group) and sex. http://www.stat.go.jp/english/data/jinsui/tsuki/ [cited 2018 November 4].

2 Ferlay J, Soerjomataram I, Dikshit R, Eser S, Mathers C, Rebelo M, Parkin DM, Forman D and Bray F: Cancer incidence and mortality worldwide: sources, methods and major patterns in GLOBOCAN 2012. Int $\mathrm{J}$ cancer 136: E359-386, 2015. PMID:25220842. DOI:10.1002/ijc. 29210

3 Siegel RL, Miller KD and Jemal A: Cancer statistics, 2017. CA Cancer J Clin 67: 7-30, 2017. PMID:28055103. DOI:10.3322/ caac. 21387

4 The Editorial Board of the Cancer Statistics in Japan: Cancer statistics in Japan -2017 Foundation for Promotion of Cancer Research. https://ganjoho.jp/en/professional/statistics/brochure/ 2017_en.html [cited 2018 November 4].

5 Vlacich G, Samson PP, Perkins SM, Roach MC, Parikh PJ, Bradley JD, Lockhart AC, Puri V, Meyers BF, Kozower B and Robinson CG: Treatment utilization and outcomes in elderly patients with locally advanced esophageal carcinoma: a review of the National Cancer Database. Cancer Med 6: 2886-2896, 2017. PMID:29139215. DOI:10.1002/cam4.1250

6 Law S, Wong KH, Kwok KF, Chu KM and Wong J: Predictive factors for postoperative pulmonary complications and mortality after esophagectomy for cancer. Ann Surg 240: 791-800, 2004 PMID:15492560. DOI:10.1097/01.sla.0000143123.24556.1c

7 Cooper JS, Guo MD, Herskovic A, Macdonald JS, Martenson JA, Al-Sarraf M, Byhardt R, Russell AH, Beitler JJ, Spencer S, Asbell SO, Graham MV and Leichman LL: Chemoradiotherapy of locally advanced esophageal cancer: long-term follow-up of a prospective randomized trial (RTOG 85-01). Radiation Therapy Oncology Group. JAMA 281: 1623-1627, 1999. PMID:10235156. DOI:10.1001/jama.281.17.1623

8 Minsky BD, Pajak TF, Ginsberg RJ, Pisansky TM, Martenson J, Komaki R, Okawara G, Rosenthal SA and Kelsen DP: INT 0123 (Radiation Therapy Oncology Group 94-05) Phase III trial of combined-modality therapy for esophageal cancer: high-dose versus standard-dose radiation therapy. J Clin Oncol 20: 11671174, 2002. PMID:11870157. DOI:10.1200/JCO.2002.20.5.1167

9 National Comprehensive Cancer Network. NCCN Clinical Practice Guidelines in Oncology: Esophageal and esophagogastric junction cancers, version 2, 2018. JNCCN. Available from: https://ww w.nccn.org/professionals/physician _gls/pdf/esophageal_blocks.pdf [cited 2018 November 17].

10 Suzuki G, Yamazaki H, Aibe N, Masui K, Shimizu D, Kimoto T, Nishimura T, Nakashima A, Takenaka T, Dohi O, Ishikawa T and Yamada K: Radiotherapy for T1N0M0 esophageal cancer: Analyses of the predictive factors and the role of endoscopic submucosal dissection in the local control. Cancers (Basel) 10: 259, 2018. PMID:30081489. DOI:10.3390/cancers10080259

11 Suzuki G, Yamazaki H, Aibe N, Masui K, Sasaki N, Shimizu D, Kimoto T, Shiozaki A, Dohi O, Fujiwara H, Ishikawa T, Konishi H, Naito Y, Otsuji E and Yamada K: Endoscopic submucosal dissection followed by chemoradiotherapy for superficial esophageal cancer: choice of new approach. Radiat Oncol 13: 246, 2018. PMID:30547811. DOI:10.1186/s13014018-1195-7

12 Sobin LH, Gospodarowicz MK and Wittekind C (eds): International Union Against Cancer (UICC). TNM classification of malignant tumors. 7th edn. New York, Wiley-Blackwell, 2009.

13 Kanda Y: Investigation of the freely available easy-to-use software 'EZR' for medical statistics. Bone Marrow Transplant 48: 452458, 2013. PMID:23208313. DOI:10.1038/ bmt.2012.244

14 Zhao L, Zhou Y, Pan H, Yin Y, Chai G, Mu Y, Xiao F, Lin SH and Shi M: Radiotherapy alone or concurrent chemoradiation for esophageal squamous cell carcinoma in elderly patients. J Cancer 8: 3242-3250, 2017. PMID:29158796. DOI: 10.7150/ jca.20835

15 Tougeron D, Hamidou H, Scotté M, Di Fiore F, Antonietti M, Paillot B and Michel P: Esophageal cancer in the elderly: An analysis of the factors associated with treatment decisions and outcomes. BMC Cancer 10: 510, 2010. PMID:20868479. DOI:10.1186/1471-2407-10-510

16 Guttmann DM, Mitra N, Metz JM, Plastaras J, Feng W and Swisher-McClure S: Neoadjuvant chemoradiation is associated with improved overall survival in older patients with esophageal cancer. J Geriatr Oncol 9: 40-46, 2018. PMID:28887066. DOI:10.1016/j.jgo.2017.08.010

17 Li X, Zhao LJ, Liu NB, Zhang WC, Pang QS, Wang P and Yuan ZY: Feasibility and efficacy of concurrent chemoradiotherapy in elderly patients with esophageal squamous cell carcinoma: A respective study of 116 cases from a single institution. Asian Pacific J Cancer Prev 16: 1463-1469, 2015. PMID:25743816. DOI:10.7314/APJCP.2015.16.4.1463

18 Tougeron D, Di Fiore F, Thureau S, Berbera N, Iwanicki-Caron I, Hamidou H, Paillot B and Michel P: Safety and outcome of definitive chemoradiotherapy in elderly patients with oesophageal cancer. Br J Cancer 99: 1586-92, 2008. PMID: 19002180. DOI:10.1038/sj.bjc.6604749

19 Zhou YC, Chen LL, Xu HB, Sun Q, Zhang Q, Cai HF and Jiang $\mathrm{H}$ : Aging-related prognosis analysis of definitive radiotherapy for very elderly esophageal cancer. Cancer Med 7: 1837-1844, 2018. PMID:29608256. DOI:10.1002/cam4.1456

20 Mak RH, Mamon HJ, Ryan DP, Miyamoto DT, Ancukiewicz M, Kobayashi WK, Willett CG, Choi NC, Blaszkowsky LS and Hong TS: Toxicity and outcomes after chemoradiation for esophageal cancer in patients age 75 or older. Dis esophagus Off J Int Soc Dis Esophagus 23: 316-323, 2010. PMID: 19788436. DOI:10.1111/j.1442-2050.2009.01014.x

21 Anderson SE, Minsky BD, Bains M, Hummer A, Kelsen D and Ilson DH: Combined modality chemoradiation in elderly oesophageal cancer patients. Br J Cancer 96: 1823-1827, 2007. PMID:17533399. DOI:10.1038/sj.bjc.6603821

22 Go SI, Sup Lee W, Hee Kang M, Song HN, Jin Kim M, Jeong Lee M, Kim HG, Won Lee G, Hun Kang J, Lee JH, Mun Kang K, Jeon KN, Min Cho J, Tae Jung W and Hyuck Ko G: Response to concurrent chemoradiotherapy as a prognostic marker in elderly 
patients with locally advanced esophageal cancer. Tumori 98: 225 232, 2012. PMID:22677989. DOI:10.1700/1088.11934

23 Song $T$, Zhang $X$, Fang $M$ and $\mathrm{Wu} S$ : Concurrent chemoradiotherapy using paclitaxel plus cisplatin in the treatment of elderly patients with esophageal cancer. Onco Targets Ther 8 : 3087-3094, 2015. PMID:26543377. DOI:10.2147/OTT.S92537

24 Huang S, Zheng S, Gong T, Ma H, Ke Y, Zhao S, Wang W, Jia L and Zhang X: Survival benefit evaluation of radiotherapy in esophageal cancer patients aged 80 and older. Oncotarget 8 : 112094-112102, 2017. PMID:29340114. DOI:10.1242/ jeb.082925

25 van Deudekom FJ, Klop HG, Hartgrink HH, Boonstra JJ, Lips IM, Slingerland M and Mooijaart SP: Functional and cognitive impairment, social functioning, frailty and adverse health outcomes in older patients with esophageal cancer, a systematic review. J Geriatr Oncol 9: 560-568, 2018. PMID:29680585. DOI:10.1016/j.jgo.2018.03.019

26 Zhang P, Xi M, Zhao L, Shen JX, Li QQ, He LR, Liu SL and Liu MZ: Is there a benefit in receiving concurrent chemoradiotherapy for elderly patients with inoperable thoracic esophageal squamous cell carcinoma? PLoS One 9: e105270, 2014. PMID:25133495. DOI:10.1371/journal.pone.0105270

27 Hurria A, Togawa K, Mohile SG, Owusu C, Klepin HD, Gross CP, Lichtman SM, Gajra A, Bhatia S, Katheria V, Klapper S, Hansen K, Ramani R, Lachs M, Wong FL and Tew WP: Predicting chemotherapy toxicity in older adults with cancer: a prospective multicenter study. J Clin Oncol 29: 3457-3465, 2011. PMID:21810685. DOI:10.1200/JCO.2011.34.7625

28 Hurria A, Wong FL, Villaluna D, Bhatia S, Chung CT, Mortimer J, Hurvitz S and Naeim A: Role of age and health in treatment recommendations for older adults with breast cancer: the perspective of oncologists and primary care providers. J Clin Oncol 26: 5386-5392, 2008. PMID:18955446. DOI:10.1200/ JCO.2008.17.6891
29 Liu M, Zhao K, Chen Y and Jiang GL: Evaluation of the value of ENI in radiotherapy for cervical and upper thoracic esophageal cancer: a retrospective analysis. Radiat Oncol 9: 232, 2014. PMID:25344056. DOI:10.1186/s13014-014-0232-4

30 Wang X, Miao C, Chen Z, Li W, Yuan S, Yu J and Hu X: Can involved-field irradiation replace elective nodal irradiation in chemoradiotherapy for esophageal cancer? A systematic review and meta-analysis. Onco Targets Ther 10: 2087-2095, 2017. PMID:28442917. DOI:10.2147/OTT.S130285

31 Chang CL, Tsai HC, Lin WC, Chang JH, Hsu HL, Chow JM, Yuan KSP, Wu ATH and Wu SY: Dose escalation intensitymodulated radiotherapy-based concurrent chemoradiotherapy is effective for advanced-stage thoracic esophageal squamous cell carcinoma. Radiother Oncol 125: 73-79, 2017. PMID:28923576. DOI: $10.1016 /$ j.radonc .2017 .08 .025

32 Chen CY, Li CC and Chien CR: Does higher radiation dose lead to better outcome for non-operated localized esophageal squamous cell carcinoma patients who received concurrent chemoradiotherapy? A population based propensity-score matched analysis. Radiother Oncol 120: 136-139, 2016. PMID:27207358. DOI:10.1016/j.radonc.2016.04.042

Received January 30, 2019

Revised February 18, 2019

Accepted February 19, 2019 